\title{
Learning in Crisis: Training Students to Monitor and Address Irresponsible Knowledge Construction by US Federal Agencies under Trump
}

\author{
Chris TirRell, LaUra Senier, SARA Wylie, Cole Alder, \\ GRACE POUdRIER, JESSE DiVALLI \\ NORTHEASTERN UNIVERSITY
}

\author{
MARCY BECK', ERIC NOST, ROB BRACKETT, GRETCHEN GEHRKE \\ ENVIRONMENTAL DATA AND GOVERNANCE INITIATIVE
}

\begin{abstract}
Immediately after President Trump's inauguration, US federal science agencies began deleting information about climate change from their websites, triggering alarm among scientists, environmental activists, and journalists about the administration's attempt to suppress information about climate change and promulgate climate denialism. The Environmental Data \& Governance Initiative (EDGI) was founded in late 2016 to build a multidisciplinary collaboration of scholars and volunteers who could monitor the Trump administration's dismantling of environmental regulations and science deemed harmful to its industrial and ideological interests. One of EDGI's main initiatives has been training activists and volunteers to monitor federal agency websites to identify how the climate-denialist ideology is affecting public debate and science policy. In this paper, we explain how EDGI's web-monitoring protocols are being incorporated into college curricula and how, in this way, EDGI's work aligns with STS work on "critical making" and "making and doing." EDGI's work shows how STS scholars can establish new modes of engagement with the state that demand a more transparent and trustworthy relationship with the public, creating spaces where the public can define and demand responsible knowledge practices and participate in the process of creating STS inspired forms of careful, collective, and public knowledge construction.
\end{abstract}

\section{Keywords}

critical making; making and doing; data justice; knowledge production; climate denial

\section{Introduction}

Following President Donald Trump's inauguration, US federal science agencies immediately began scrubbing information about climate change from their websites. In some cases, text about climate change was altered, but in more extreme cases, entire sections of federal websites were

. Chris Tirrell, Email: tirrell.c@husky.neu.edu

2Marci Beck, Email: marcy.beck@gmail.com

Copyright (C) 2020 (Chris Tirrell, Laura Senier, Sara Wylie, Cole Alder, Grace Poudrier, Jesse DiValli, Marci Beck, Eric

Nost, Rob Brackett, and Gretchen Gehrke). Licensed under the Creative Commons Attribution Non-commercial No Derivatives (by-nc-nd). Available at estsjournal.org. 
removed. For instance, in April 2017 the Environmental Protection Agency [EPA] removed its subdomain "epa.gov/climatechange" and it has not been relaunched (Rinberg et al. 2018). The EPA explains these changes as consistent with "the agency's new direction under President Donald Trump and [former] Administrator Scott Pruitt" (US EPA 2017). Many scientists, environmental activists, and journalists expressed alarm about the Trump administration's effort to suppress information about climate change (Carter et al. 2017). In late 2016, a multidisciplinary group of STS scholars, scientists, programmers, and professionals established the Environmental Data \& Governance Initiative (EDGI) out of concern "that vital environmental data and other information from government websites might be erased or altered, as well as a general concern about the future of...environment-related agencies"' (EDGI 2019). A major EDGI initiative is monitoring federal websites for changes to information about the environment, energy, and climate change, in order to track corporate influence over science policy and the promulgation of climate denialism (Oreskes and Conway 2010; Knutson et al. 2018; Nost et al. 2018). EDGI's web-monitoring team developed methods for tracking federal website changes, training people to web-monitor (so they know which websites to monitor and how to interpret and contextualize any changes), allowing the group to document the impacts that the Trump administration's ideology is having on public environmental information.

\section{CN POlitics 45 congress $\quad$ Supreme court $\quad$ FActs First 2020 ELECTION}

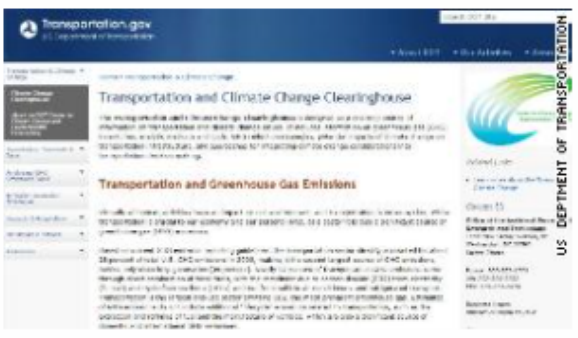

The Environmental Data and Governance Initiative -- a group that monitors federal agency websites and changes to those sites, along with archiving environmental data on federal government websites -has identified at least 16 instances of climate change information being scrubbed from federal government websites under the Trump administration.

In January, CNN reported on a study by the group that found the administration had eliminated or replaced references to climate change, renewable energy and similar topics on federal agency websites including the Department of Energy, the Environmental Protection Agency, the Interior Department, the State Department and the Department of Transportation.

Figure 1. CNN reports on EDGI's findings related to federal government websites' use of terms such as climate change and renewable energy.

The climate denial movement's overt entrée into the White House and across the US Cabinet with the election of Donald Trump may be seen as an apex of corporate public relations influence over knowledge and policy making (Oreskes and Conway 2010; Kahn 2016; Carasik 
2016); the Trump administration's deletion of information about the climate crisis highlights the dramatic ways that fossil fuel interests and the state are using the internet to shape public debate and policy. Amidst the converging crises of climate change and disinformation, EDGI's webmonitoring illustrates how STS can raise and address "matters of public concern" by developing new systems for accountable knowledge construction ( $c f$ Latour 2004). Analyzing a spring 2019 Northeastern University graduate "Society, Health and the Environment" class's experience of EDGI's web-monitoring as a form of "critical making" and "making and doing" in STS, we propose that it exemplifies an STS approach to responsive and responsible knowledge production that demands a more transparent and trustworthy relationship between the state and the public (Ratto et al. 2014; Lee Downey and Zuiderent-Jerak 2017). Bringing these tools into the classroom can give students skills to assess the state's practices of disinformation, foster critical thinking, and combat the sense of futility often experienced when learning about the entrenched power asymmetries that hinder progress on mitigating climate change (Rinberg et al. 2018). Organizations such as EDGI are helping to establish new modes of engagement with the state, and making spaces where the public can not only define and demand responsible knowledge practices, but also participate in the process of creating that knowledge.

\section{EDGI and Critical Making}

EDGI's work is propelled in part by STS scholarship on "critical making" and "making and doing," which highlight the importance of moving beyond traditional academic boundaries, hierarchies, and norms to actively build alternative forms of technoscience. Ratto, Wylie, and Jalbert define critical making as "a research program that explores the range of practices and perspectives connecting conceptual critique and material practice... the impetus for this endeavor comes from the idea that technoscience... requires the development of new relationships between traditional forms of critique and critiques [that are] embedded in material interventions" (2014: 86). To approach research as an activity that extracts knowledge from the material world and produces written outputs solely for elite audiences is, in this light, inherently limited: researchers are not outside of their material worlds but entangled in them. Therefore, as well as writing about the politics enacted by technical systems, scholars can actively remake socio-technical systems with alternative politics.

Critical making can also advance pedagogy or teaching by practically illustrating how social relationships are configured in part through technical systems, particularly those that create and sustain power asymmetries. While lectures, examinations, and paper writing have merits, an overreliance on them can lead to abstraction, busy work, or-more troubling — apathy and disempowerment, as they do not provide students with the opportunity to disrupt the forces that create inequity. This is particularly salient in teaching about climate denial, environmental injustice, and the lived reality of health disparities where students can become despondent, particularly if they repetitively learn they are part of marginalized, "harmed" communities (Tuck 2009). Teaching STS through critical making can engage students as agents in the deconstruction and reconstruction of knowledge production. 
Kenny, Liboiron, and Wylie (2014) piloted this approach with a project where students built thermal flashlights whose color changes based on the surface temperature of the object illuminated. Using long-exposure photography, thermal flashlights can be used to paint temperature data with different colors of light onto surfaces to generate thermal data images. Students in two different universities used them to visualize and develop knowledge about thermal data in their environments, such as the variance of temperatures in dorm refrigerators, the efficiency of energy use on campus, and thermal pollution at a local power plant. This project allowed "students and instructors [to] 'see' and investigate energy and power relations within technical systems of which they may not have been previously very aware" (2014: 4). Whereas the thermal flashlight allowed students to make new knowledge about their environments, EDGI's web-monitoring is enabling students to make knowledge about the state.

EDGI's web-monitoring exemplifies critical making and engaged pedagogy in four ways. First, web-monitoring moves beyond simply arguing that the federal government should have a coherent web history, by developing and enacting a socio-technical system that actively helps to build one. Second, EDGI is a novel integration of multi-sited academic-public research supported by a non-profit umbrella. EDGI's web-monitoring would not be possible without the social organization of over 150 people at multiple institutions and online platforms that create open and democratic collaboration among academics, programmers, librarians, business people, non-profit researchers, geographers, and many volunteers (Kimura \& Kinchy 2016; Vera et al. 2019). Third, EDGI has created novel knowledge validation routines for web-monitoring analysts to identify, contextualize, and rapidly report their findings. As described below, this included a collaborative vetting process to determine a change's significance, as well as presenting time-date stamped evidence that anyone can inspect. Fourth, EDGI has accelerated knowledge production-a crucial point, given how quickly the Trump administration has curtailed dissemination of knowledge that is harmful to its industrial and ideological interests. EDGI's rapid response has informed hundreds of news articles and allowed journalists to bring changes to the public's attention almost as soon as they occur, and produced questions that require lengthier research investigations (Knutson et al. 2018; Braun et al. 2019). In sum, EDGI exemplifies collaborative critical learning and making in the midst of these crises by actively figuring out new forms of public knowledge production suited to this rapidly changing sociopolitical environment in which the state limits public access to information and creates disinformation.

\section{Pedagogy in Action}

EDGI's web-monitoring uses Scanner, an open-source, custom-built online platform that allows users to simultaneously view side-by-side snapshots of a webpage as it appeared at two different times. These snapshots are recorded by a commercial system-Versionista or the Internet Archive's Wayback Machine (see Figure 2). Text or links that have been removed are highlighted in red and items that have been added are highlighted in green. 


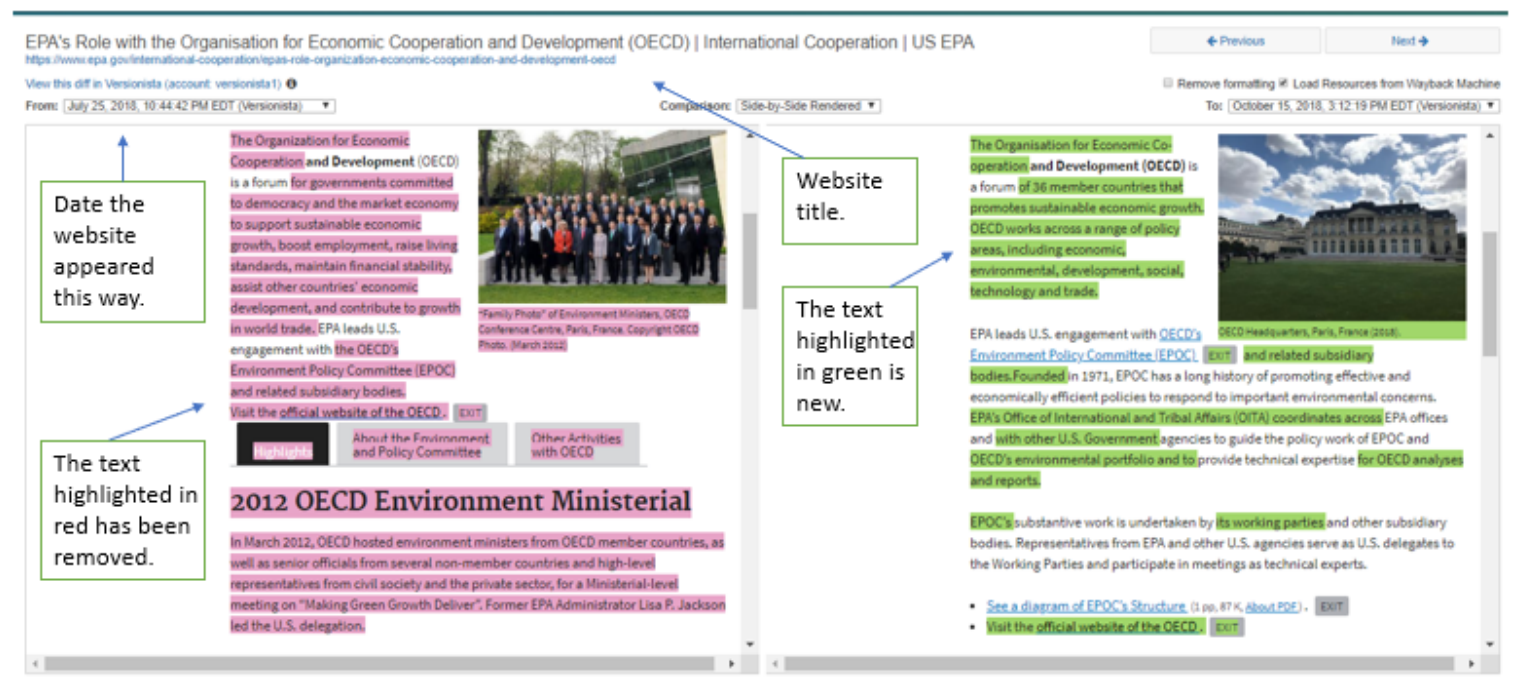

Figure 2. Scanner - EDGI's Website Monitoring Platform

Web-monitoring analysts are assigned a domain, and each week Scanner generates a spreadsheet that provides automated details about text differences and preliminary assessments of their importance in each domain (see Figure 3).

Web-monitoring analysts review pages flagged in Scanner by comparing the before and after versions, $\log$ results in an individual analyst spreadsheet and document any major changes in a collaborative "important changes" document (see Figure 4). Sometimes the changes made are clearly insignificant (e.g., changes to the date of the page's last update), but at other times changes are clearly quite significant (e.g., removal of whole webpages). Many cases fall between these extremes, and analysts must assess and contextualize the changes when reporting them. The assessment of "significance" is one of the most important and debated challenges within EDGI's web-monitoring team. It brings alive STS questions of which knowledge counts for whom and when, and highlights the problem of whether a change can speak for itself or whether its meaning is interpretable only in a particular socio-political context. Significant changes must be selected from a shifting and at present unknowable morass of federal websites-there is no map of all federal websites, and EDGI watches a subset of $\sim 25,000$ websites. Based on the sample of domains that EDGI has selected to follow, the web-monitoring team identifies changes that seem important based on analysts' prior knowledge of issues such as climate denial. Hence the slippery threshold between "evidence" and "interpretation" is negotiated collectively on a caseby-case basis rather than by following a prescribed template or "objective" view of a coherent whole. EDGI's web-monitoring community works through the online collaboration and chat software Slack and meets weekly online, so new web-monitoring analysts work with more experienced analysts to learn what types of changes are likely to be significant and how to contextualize them for a public audience. 


\begin{tabular}{|c|c|c|c|c|c|c|}
\hline Index & UUID & Output Date/Time & Agency & Site Name & Page name & Page View URL Last Two Latest 1 Date Found \\
\hline 1 & $2 \mathrm{~d} 47 \mathrm{f} 99 \mathrm{e}$ & €2019-04-02T10:45Z & ZEPA & epa.gov-water & About the Safe and $\vdots$ https: $/ / w w w$. & https://versionist: https://mor https://n 2019-03-29 \\
\hline 2 & decc & $2019-04-02 T 10: 45 Z$ & ZEPA & pa.gov--water & ure I US EPA httl & nist: htt \\
\hline 3 & & & EPA & ter & $\in \mathrm{http}$ & 26 \\
\hline 4 & 21be? & & ZEPA & epa.gov--water & 3 o. http: & niste $\underline{h}$ \\
\hline 5 & acbeb & b2019- & 2 EPA & epa.gov--water & ocur http: & hittr \\
\hline 6 & $\mathrm{~d} 50 \mathrm{c} 4$ & +2019 & EPA & pa.gov--water & we hitt & 29 \\
\hline 7 & 5e3fof & & EPf & water & . & 30. \\
\hline 8 & e4248c & & $2 \mathrm{EP}$ & vater & Er hitt & hist: \\
\hline 9 & 5d63ada & 201 & EPA & epa.gov-water & Se https & 26 \\
\hline 10 & a4369 & & ZEP & pa.gov--water & lat $\underline{\mathrm{h}}$ & mor $h$ \\
\hline 11 & fe $45 d$ & 20 & EP & vater & 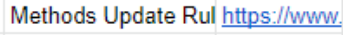 & 31 \\
\hline 12 & $469 \mathrm{cf}$ & & $2 \mathrm{EPA}$ & epa.g & er hit & 30 \\
\hline 13 & $68 \mathrm{~d} 7381$ & 1201 & EPA & epa.gov-water & nents https://www. & nistt $\underline{\text { https: } / / \mathrm{mor}} \underline{\mathrm{ht}}$ \\
\hline 14 & $22 \mathrm{co}$ & & $\mathrm{EF}$ & water & Se ht & 1 \\
\hline 15 & $9 \mathrm{~b} 806 \mathrm{~d} 1$ & & ZEP & pa.gov--water & es $h$ & \\
\hline 16 & 3efe 5 fe 3 & B 2019 & 2 EPA & epa.gov--water & il and Grease Mea: https://www. & 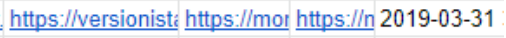 \\
\hline 17 & $2 \mathrm{fe} 6 \mathrm{dc} 73$ & 20 & EPA & epa.gov--water & ter Act Sec https: / /ww & ioniste https: $/ / \mathrm{mor}$ https: $/ / / \mathrm{n}$ \\
\hline 18 & $3698 b f 4 \varepsilon$ & & 2EPA & epa.gov-water & מ & ttps://mor https://n 2019-04-01. \\
\hline
\end{tabular}

Figure 3. Snapshot of Scanner's tabular output. From this spreadsheet, users can navigate to Scanner for side by side visual inspection

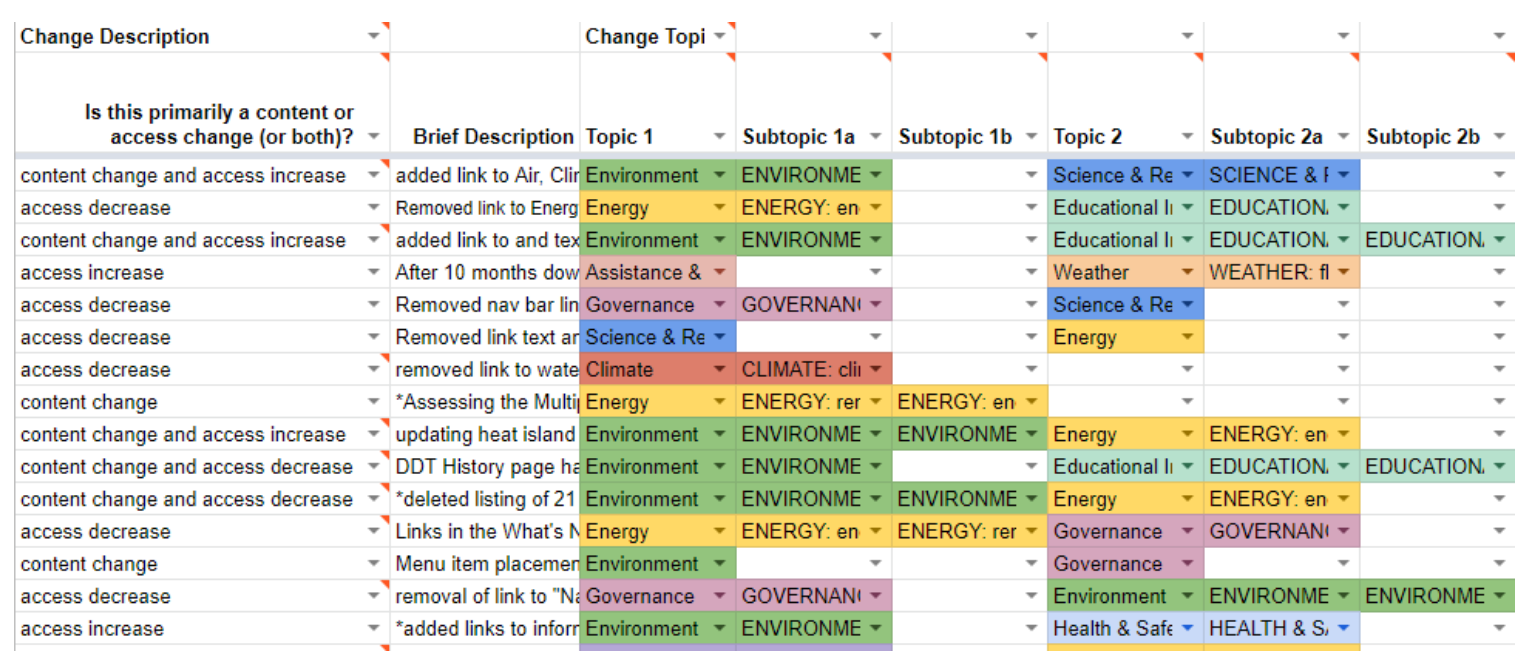

Figure 4. Snapshot of EDGI's “Important Changes" document.

Two classes have now integrated web-monitoring into their curriculum-a course Knowing Climate Changes on community-engaged research at the University of Michigan and a graduate and undergraduate seminar in Environment, Health, and Society at Northeastern University. EDGI's platform pushed students to develop both individual and collective

${ }_{3}^{3}$ https: / / envirodatagov.org / web-monitoring-in-the-classroom-builds-information-literacy-civicengagement/ 
responsibility for their research. For the Northeastern course each student was assigned a federal government domain and reported results to the group weekly. The syllabus included readings from STS, sociology, anthropology, and public health, and covered a range of topics such as environmental justice, state surveillance, consumer society, the manipulation of media, and data justice. Along with weekly readings, students participated in web-monitoring and communicated with others in EDGI's network. Each person identified changes on the sites they were monitoring, thus creating new knowledge about the state's information and disinformation practices.

Web-monitoring put students in the position of identifying new knowledge about the state at the same time that they were learning about the historical symbiotic relationship between the state and corporate sector, and how the state-corporate nexus has a long tradition of extractive research to make knowledge about people as citizens and consumers. As one student of this class describes: "As an undergrad sociology student, the opportunity to participate in web-monitoring with the diverse body of EDGI members was one of the first instances I had to escape the often transactional and disempowering nature of a traditional college curriculum. More than just a student working toward a grade, I was an accountable member of a professional community - of a movement--which relied on my diligent and critical efforts. I was an active defender against corporate influence over democratic processes, a maker of knowledge" (Cole Alder, Northeastern undergraduate 2019). Students who took the University of Michigan course had similar experiences, highlighting how monitoring websites in conjunction with coursework helped them to make connections between environmental problems they studied and ongoing problems related to climate change and Superfund sites. In a podcast discussing their class, the students described how they were able to connect issues of the past such as the Love Canal incident in Niagara, NY with the water crisis in Flint, MI, and to connect issues of legacy and current pollution with the threat of climate change, all in the context of efforts by the current administration to downplay both threats (WCBN 2018).

One student in the Northeastern University class monitored the Department of the Interior (DOI), which updated its website to reflect the nomination of new DOI Secretary David Bernhardt (who replaced the controversial Secretary Zinke in late 2018). Notably, Bernhardt's official bio omitted information about his potential conflicts of interest (due to his many years of work for fossil fuel and other industries). The student posted a blog about the DOI's presentation of Bernhardt that was viewed over 11,000 times on Twitter during his nomination hearings. The post raised the underlying question of the state's duty to accurately present officials' backgrounds so that the public may adequately assess their actions and potential conflicts. While it did not and could not prevent his nomination, this post did generate important public conversation about an otherwise undiscussed aspect of this controversy.

Beyond pointing out omissions and changes to public knowledge, web-monitoring is helping to conceptualize how federal websites should be managed. Another student from Northeastern University helped to develop a preliminary set of recommendations for better

“ https:/ / docs.google.com/document/d/1GII0NuCV9jmqlw2jzwg_WrR2ZDe4fAFLzGB9CDWoshE/edit ${ }^{s}$ https: / / envirodatagov.org/worked-for-entities-accused-of-violating-doi-regulations-and-other-omissionsin-the-nominated-secretary-for-the-interior-david-bernhardts-official-bio/ 
federal archiving and web mapping practices based on her own experience monitoring the globalchange.gov domain. There are currently minimal regulations regarding the alteration or removal of content or data hosted on government websites. In collaboration with EDGI, the student developed ten recommendations to improve federal web archiving and mapping practices. These included a call for citations for empirical statements and data, statements of authorship, the publication of data on the civic uses of federal websites, and the creation of a "changelog" to offer public information about when, where, and why changes to federal websites are made. These guidelines are being further developed within EDGI, which plans to publish them and help improve government website management standards.

\section{Conclusion}

Critical making and engaged pedagogy are about more than simply acquiring specific skills. EDGI puts critical making into action because of an urgent need to challenge the current antidemocratic moment and to address public matters of concern. EDGI's web-monitoring exemplifies work that bridges the gaps that usually separate academics and the public, and makes possible collaborative, networked futures. The students in the classes we describe here engaged directly in defining responsible construction of knowledge, and even went a step further by creating new knowledge about the state's disinformation practices. EDGI's web-monitoring has informed hundreds of news articles, active public debates on Twitter and may even be influencing EPA action; as EEE News reports, an EPA staffer said: "No one is willing to touch the website because everyone's afraid of the news stories that say, 'EPA changed this." This work actively turns the surveillance paradigm on its head, enabling the public to monitor its state rather than being only subject to intrusive data gathering by states and companies (Foucault 2012; Vaidhyanathan 2011; Dencik et al. 2016). But EDGI and the Northeastern class ended the semester interested in asking how can this be more than Foucauldian surveillance leading to infinite cycles of paranoia and power-plays? How can the work of EDGI be part of developing new practices of collaborative care for our knowledge production as STS researchers are calling for (Haraway 2003)? Puig de la Bellacasa fittingly describes care as "a vital affective state, an ethical obligation and a practical labor" (2012: 197). EDGI helps realize the practical labor side of this ethical obligation to responsibly produce and share knowledge about our collective conditions.

Scientific knowledge production was hardly innocent and harmless before the advent of Trump, so how can STS inform the development of more responsive, responsible and careful knowledge production (Murphy 2017; Braun 2014; Smith 2013)? EDGI argues it is leading the way in both conceptualizing and enacting different ways of collective knowing (Dencik et al. 2016; Taylor 2017). In that spirit we end with an invitation for others teaching STS to try webmonitoring in your classes, as a means of supporting your students, whether they are actively striking in the streets or struggling with apathy and despair. Come help us figure out new ways of responding to these crises, in ways that express care for how we make and share knowledge, 
and that use digital systems to improve rather than impair our collective memories and advance a more just, equitable and less harmful future.

\section{Author Biography}

Chris Tirrell is a sociology PhD student at Northeastern University and was a member of EDGI's web monitoring team during the spring of 2019, where he monitored changes made to the EPA's International Cooperation subdomain. His current research focuses on the roles that social media and personal branding play for workers in the $21^{*}$ century, specifically regarding the culture industry.

\section{Author Biography}

Laura Senier is an Associate Professor of Sociology and Health Sciences at Northeastern University and a Core Faculty member at the Social Science Environmental Health Research Institute (SSEHRI). Her research has identified barriers in research translation, or the migration of scientific knowledge into practical applications, and community mobilization in response to environmental injustice. She is collaborating with two groups of teen environmental justice activists on a study to examine the effects of green and blue recreational amenities on mental health and emotional well-being among urban teens.

\section{Author Biography}

Sara Wylie is an Assistant Professor of Sociology/Anthropology and Health Sciences in Northeastern University's Social Science Environmental Health Research Institute. Wylie is a cofounder of Public Lab and EDGI, the Environmental Data and Governance Initiative. Wylie seeks to develop research tools, collaborations and platforms for studying and creating accountability for the fossil fuel and allied petrochemical industries. Her book Fractivism: Corporate Bodies and Chemical Bonds with Duke University Press (2018) analyzes the U.S. boom in unconventional energy production.

\section{Author Biography}

Cole Alder is a $4^{\text {" }}$ year undergraduate student in sociology with minors in ethics and environmental studies at Northeastern University. Since January of 2018, he has worked as a research assistant under Dr. Phil Brown and Dr. Alissa Cordner's PFAS Project Lab, a group of faculty, post-doctoral scholars, graduate students, and undergraduates affiliated with the Social Science Environmental Health Research Institute at Northeastern University. Studying the social discovery of a class of emerging contaminants known as per- and polyfluoroalkyl substances (PFAS), the lab investigates the emergence of lay awareness, government involvement, media 
coverage, lititgation, and advocacy surrounding a national PFAS drinking water contamination crisis.

\section{Author Biography}

Grace Poudrier is a sociology PhD student at Northeastern University and a member of the Social Science Environmental Health Research Institute and the Environmental Data \& Governance Initiative. She is interested in how embodied illness experience and citizen science are deployed to challenge orthodox science and knowledge-making practices, as well as to evince corporate accountability for chemical and environmental violence.

\section{Author Biography}

Jesse is a PhD student at Northeastern University, where he focuses on research related to riskscapes, sustainability, and effects of rapid neighborhood change in urban environments. He is a member of the Social Science Environmental Research Institute on its Water Equity Team, supporting research on social issues related to urban water resources and provision.

\section{Author Biography}

Marcy Beck has been a member of EDGI's web monitoring team since September 2017. She served as Program Development Leader for energy efficiency and climate change programs at Lawrence Berkeley National Laboratory and is currently a working Board Member of Stewards of the Coast and Redwoods in northern California.

\section{Author Biography}

Eric Nost has been a member of EDGI's web monitoring team since February 2017 and is an Assistant Professor in the Department of Geography, Environment, and Geomatics at the University of Guelph. He researches how data and digital technologies inform environmental governance and has previously collaborated in efforts to visualize US EPA data on the North American hazardous waste trade (https:/ / geography.wisc.edu/hazardouswaste/).

\section{Author Biography}

Rob Brackett has been a member of EDGI's web monitoring team since February 2017 and works as a software engineering consultant. He maintains the open-source software projects that support EDGI's web monitoring work and helps to guide the team's technical analysis efforts. 


\section{Author Biography}

Gretchen Gehrke is a cofounder of EDGI and leads EDGI's web monitoring team. Prior to her work with EDGI, Gehrke researched environmental transformations and remediation of toxic trace metals and supported communities in conducting low cost environmental studies.

\section{Acknowledgements}

EDGI's web-monitoring team is a highly interdisciplinary and unique effort to integrate volunteers, environmental and social scientists, and software developers to develop novel forms of governmental transparency. The idea developed from conversations among the group that started EDGI and was implemented by geographer Rebecca Lave and scientist Gretchen Gerhke. Toly Rinberg, a graduate student in physics at Harvard, played an important leadership role in its first year helping develop protocols for tracking web changes along with Maya Anjur-Dietrich and Andrew Bergman (also graduate students at Harvard). A public call for volunteers resulted in a remarkable mix of professionals including a public library metadata services manager (Sara Rubinow), a businessman (Jake Wylie), a former national laboratory leader of energy and environmental program development (Marcy Beck) along with a host of others from many walks of life: Justin Derry, Anastasia Aizman, Madelaine Britt, Janak Chadha, Morgan Currie, Sara Johns, Abby Klionsky, Stephanie Knutson, Katherine Kulik, Aaron Lemelin, Eric Nost, Kendra Ouellette, Lindsay Poirier, Justin Schell, Lizz Ultee, Julia Upfal, Tyler Wedrosky. The efforts of these analysts are supported by a primarily volunteer community of software developers-Raymond Cha, Dan Allan, Jason Sherman, Rob Brackett, Patrick Connolly and Kevin Nguyen-and a collaboration with the Internet Archive's Wayback Machine. The first course to integrate EDGI's web-monitoring was organized by Lizz Ultee from the University of Michigan in partnership with Justin Schell, Director of the Design Lab at the University of Michigan Shapiro Undergraduate Library. Their students produced a blog and podcast about their experiences. We gratefully acknowledge funding from the National Institute of Environmental Health Sciences of the National Institutes of Health (T32ES023679).

\section{References}

Braun, Lundy. Breathing race into the machine: The surprising career of the spirometer from plantation to genetics. U of Minnesota Press, 2014.

Braun, Steven, Kelsey Breseman, Leif Frederickson, Gretchen Gehrke, Stephanie Knutson, Michelle Murphy, Kevin Nguyen, Chris Sellers, Nick Shapiro, Kyala Shea, Marianne Sullivan, Aparna Sundar, Sara Wylie, and EDGI. "EDGI Annual Report 2019." Environmental Data and Governance Initiative.

\footnotetext{
${ }^{6}$ https: / / envirodatagov.org/ web-monitoring-in-the-classroom-builds-information-literacy-civicengagement/
} 
https:/ / envirodatagov.org/publication/edgi-annual-report-2019/ (accessed May 23, 2019).

Carasik, Lauren. "Donald Trump's Cabinet Bodes Ill for the Planet." (2016).

Carter, Jacob, G. Goldman, G. Reed, P. Hansel, M. Halpern, and A. Rosenberg. 2017. “Sidelining Science Since Day One: How the Trump Administration Has Harmed Public Health and Safety in Its First Six Months." Center for Science and Democracy.

Dencik, Lina, Arne Hintz, and Jonathan Cable. "Towards data justice? The ambiguity of antisurveillance resistance in political activism." Big Data \& Society 3, no. 2 (2016): 2053951716679678.

Environmental Data and Governance Initiative. "About - EDGI." https: / / envirodatagov.org/about/ (accessed May 21, 2019).

Foucault, Michel. Discipline and punish: The birth of the prison. Vintage, 2012.

Haraway, Donna Jeanne. The companion species manifesto: Dogs, people, and significant otherness. Vol. 1. Chicago: Prickly Paradigm Press, 2003.

Kahn, Brian. "What You Should Know About Trump's Cabinet and Climate." Climate Central. https:// www.climatecentral.org/news/trump-cabinet-climate-change-20920 (accessed August 16, 2019)

Kenny, Catherine, Max Liboiron, and Sara Ann Wylie. "Seeing power with a flashlight: DIY thermal sensing technology in the classroom." Social studies of science 49, no. 1 (2019): 3-28.

Kimura, Aya H., and Abby Kinchy. "Citizen science: Probing the virtues and contexts of participatory research." Engaging Science, Technology, and Society 2 (2016): 331-361.

Knutson, Stephanie, Marcy Beck, Steven Braun, Ray Cha, Lindsey Dillon, Gretchen Gehrke, Rebecca Lave, Michelle Murphy, Matt Price, Toly Rinberg, Sara Rubinow, Chris Sellers, Nick Shapiro, Kyala Shea, Lourdes Vera, Dawn Walker, Sara Wylie, and EDGI. "EDGI Annual Report 2018." Environmental Data and Governance Initiative. https:/ / envirodatagov.org/publication/edgi-annual-report-2018/ (accessed May 23, 2019).

Latour, Bruno. "Why has critique ran out of steam?." Critical inquiry 30.

Downey, Gary Lee, and Teun Zuiderent-Jerak. "Making and doing: Engagement and reflexive learning in STS." Handbook of Science and Technology Studies (2016): 223-250.

Murphy, Michelle. The economization of life. Duke University Press, 2017.

Nost, Eric, Gretchen Gehrke, and the Environmental Data and Governance Initiative Website Monitoring Team. "EPA Discontinues Updates to Climate Change Websites." Environmental Data and Governance Initiative. https:/ / envirodatagov.org/aar-9-epadiscontinues-updates-to-climate-change-websites / (accessed May 21, 2019).

Oreskes, Naomi, and Erik M. Conway. Merchants of doubt: How a handful of scientists obscured the truth on issues from tobacco smoke to global warming. Bloomsbury Publishing USA, 2011.

de la Bellacasa, Maria Puig. "'Nothing comes without its world': thinking with care." The Sociological Review 60, no. 2 (2012): 197-216.

Ratto, Matt, Sara Ann Wylie, and Kirk Jalbert. "Introduction to the special forum on critical making as research program." The information society 30, no. 2 (2014): 85-95. 
Rinberg, Toly, Maya Anjur-Dietrich, Marcy Beck, Andrew Bergman, Justin Derry, Lindsey Dillon, Gretchen Gehrke, Rebecca Lave, Chris Sellers, Nick Shapiro, Anastasia Aizman, Dan Allan, Madelaine Britt, Raymond Cha, Janak Chadha, Morgan Currie, Sara Johns, Abby Klionsky, Stephanie Knutson, Katherine Kulik, Aaron Lemelin, Kevin Nguyen, Eric Nost, Kendra Ouellette, Lindsay Poirier, Sara Rubinow, Justin Schell, Lizz Ultee, Julia Upfal, Tyler Wedrosky, Jacob Wylie, and EDGI. "The First 100 Days and Counting: Changing the Digital Climate." Environmental Data and Governance Initiative. http:/ / 100days.envirodatagov.org/ changing-digital-climate/ (accessed May 21, 2019).

Smith, Linda Tuhiwai. Decolonizing methodologies: Research and indigenous peoples. Zed Books Ltd., 2013.

Taylor, Linnet. "What is data justice? The case for connecting digital rights and freedoms globally." Big Data \& Society 4, no. 2 (2017): 2053951717736335.

Tuck, Eve. "Suspending damage: A letter to communities." Harvard Educational Review 79, no. 3 (2009): 409-428.

United States Environmental Protection Agency. "EPA Kicks Off Website Updates." https://www.epa.gov/newsreleases/epa-kicks-website-updates (accessed April 25, 2019).

Vaidhyanathan, Siva. The Googlization of everything:(and why we should worry). Univ of California Press, 2012.

Vera, Lourdes A., Lindsey Dillon, Sara Wylie, Jennifer Liss Ohayon, Aaron Lemelin, Phil Brown, Chris Sellers, Dawn Walker, and Environmental Data and Governance Initiative. "Data Resistance: A Social Movement Organizational Autoethnography of the Environmental Data and Governance Initiative." Mobilization: An International Quarterly 23, no. 4 (2018): 511-529.

WCBN. 2018. "Knowing Climate Change: A Student Panel on Accountability and Accessibility." It's Hot in Here: Environmental News, Views, and Stone Cold Grooves, University of Michigan-Ann Arbor: Ann Arbor, MI. 